(C) 2020. This manuscript version is made available under the CC-BY-NC-ND 4.0

license http://creativecommons.org/licenses/by-nc-nd/4.0/

\title{
Detection of sulfur dioxide at low parts-per-million concentrations using low-cost planar electrodes with ionic liquid electrolytes
}

\section{Authors and affiliations}

Simon Doblinger ${ }^{\mathrm{a}}$, Junqiao Lee ${ }^{\mathrm{a}}$, Zoe Gurnaha, ${ }^{\mathrm{a}}$, Debbie S. Silvester ${ }^{\mathrm{a}, *}$

${ }^{a}$ Curtin Institute for Functional Molecules and Interfaces, and School of Molecular and Life Sciences, Curtin University, GPO Box U1987, Perth, WA 6845, Australia

${ }^{\mathrm{b}}$ Department of Chemistry, University of Southampton, University Road, Southampton, SO171BJ, UK

*Corresponding author. Email: d.silvester-dean@curtin.edu.au Phone: +61 892667148

\begin{abstract}
Sulfur dioxide $\left(\mathrm{SO}_{2}\right)$ is a toxic gas at low parts-per-million $(\mathrm{ppm})$ concentrations, with a permissible exposure limit (PEL) of $2 \mathrm{ppm}$. Its detection is mandatory, particularly in the fields of occupational health and safety, and environmental pollution. In this work, ppm concentration detection of sulfur dioxide was performed in six room temperature ionic liquids (RTILs), as well as on two different electrode materials - platinum and gold - and with two different electrode geometries, i.e. macro thin-film electrodes (TFEs) and microarray thin-film electrodes (MATFEs). Calibration curves were established for 10-200 ppm $\mathrm{SO}_{2}$ using cyclic voltammetry to determine the optimum combination of RTIL, electrode surface and geometry for the sensing. The RTIL 1-butyl-1-methylpyrrolidinium bis(trifluoromethylsulfonium)imide ( $\left.\left[\mathrm{C}_{4} \mathrm{mpyrr}\right]\left[\mathrm{NTf}_{2}\right]\right)$ with a platinum thin-film electrode was found to give the best response due to the relatively low viscosity of the RTIL combined with the high sensitivity and a clean blank response. On MATFEs, deposited sulfur particles - confirmed using scanning electron microscopy (SEM) coupled to an energy dispersive spectrometer (EDS) - were found to passivate and block some of the microholes, leading to unstable longterm chronoamperometric responses. To the best of our knowledge, this is the first observation of sulfur deposition from $\mathrm{SO}_{2}$ reduction in aprotic ionic liquids. Consecutive additions of $2 \mathrm{ppm} \mathrm{SO} \mathrm{S}_{2}$ were studied in $\left[\mathrm{C}_{4} \mathrm{mpyrr}\right]\left[\mathrm{NTf} \mathrm{f}_{2}\right]$ on a TFE using long-term chronoamperometry, showing excellent reproducibility upon successive additions. This demonstrates that small volumes of RTILs can be combined with miniaturized, low-cost TFEs and applied for the reliable detection of sulfur dioxide gas at concentrations lower than the permissible exposure limit of $2 \mathrm{ppm}$.
\end{abstract}

\section{Keywords}

Sulfur dioxide; gas sensing; room temperature ionic liquids; thin-film electrodes; cyclic voltammetry; long-term chronoamperometry. 


\begin{tabular}{|c|c|}
\hline \multicolumn{2}{|l|}{ Abbreviations } \\
\hline$J$ & current density \\
\hline$\eta$ & dynamic viscosity \\
\hline $\mathrm{CV}$ & cyclic voltammetry \\
\hline EDS & energy dispersive $\mathrm{X}$-ray spectroscopy \\
\hline LTCA & long-term chronoamperometry \\
\hline MATFE & microarray thin-film electrode \\
\hline PEL & permissible exposure limit \\
\hline RTIL & room temperature ionic liquid \\
\hline SEM & scanning electrode microscopy \\
\hline $\mathrm{SO}_{2}$ & sulfur dioxide \\
\hline TFE & thin-film electrode \\
\hline$\left[\mathrm{C}_{2} \mathrm{mim}\right]\left[\mathrm{NTf}_{2}\right]$ & 1-ethyl-3-methylimidazolium bis(trifluoromethylsulfonyl)imide \\
\hline$\left[\mathrm{C}_{4} \operatorname{mim}\right]\left[\mathrm{NTf}_{2}\right]$ & 1-butyl-3-methylimidazolium bis(trifluoromethylsulfonyl)imide \\
\hline$\left[\mathrm{C}_{4} \mathrm{mim}\right]\left[\mathrm{BF}_{4}\right]$ & 1-butyl-3-methylimidazolium tetrafluoroborate \\
\hline$\left[\mathrm{C}_{4} \mathrm{mim}\right][\mathrm{FAP}]$ & 1-butyl-3-methylimidazolium tris(pentafluoroethyl)trifluorophosphate \\
\hline$\left[\mathrm{C}_{4} \mathrm{mim}\right]\left[\mathrm{NO}_{3}\right]$ & 1-butyl-3-methylimidazolium nitrate \\
\hline$\left[\mathrm{C}_{4} \mathrm{mpyrr}\right]\left[\mathrm{NTf}_{2}\right]$ & 1-butyl-1-methylpyrrolidinium bis(trifluoromethylsulfonium)imide \\
\hline$\left[\mathrm{P}_{14,6,6,6}\right]\left[\mathrm{NTf}_{2}\right]$ & trihexyltetradecylphosphonium bis(trifluoromethylsulfonyl)imide \\
\hline$\left[\mathrm{S}_{2,2,1}\right]\left[\mathrm{NTf}_{2}\right]$ & diethylmethylsulfonium bis(trifluoromethylsulfonyl)imide \\
\hline
\end{tabular}




\section{Introduction}

The reliable monitoring of air quality is a major focus of gas sensing research, especially due to the fact that some gases, even at low parts-per-million (ppm) concentrations, can cause harmful effects on nature and humans [1,2]. One of the background environmental gases is sulfur dioxide $\left(\mathrm{SO}_{2}\right)$, an invisible gas with a sharp smell that, in the presence of moisture, can cause acidic rain and damage to building materials such as limestone. $\mathrm{SO}_{2}$ is a typical by-product in petroleum refineries or fossil fuel burning power plants. It is known that $\mathrm{SO}_{2}$ is a severe threat towards air quality and health [2], therefore the release of the gas needs to be strictly regulated. It causes respiratory problems upon inhalation and at higher concentrations it can be deadly [3]. The National Institute for Occupational Safety and Health (NIOSH) defined a concentration of $100 \mathrm{ppm}$ as dangerous to life, and stated that the recommended permissible exposure limit (PEL) is 2 ppm averaged over a 10-hour work shift of 5 days per week, and a maximum of 5 ppm during any 15-minute work period. The effects on health are felt quickly - usually within 15 minutes - so a fast responding sensor for low ppm concentrations is essential.

Generally, gas sensors based on optical [4], gas chromatographic [5] or electrochemical [6] techniques have been studied extensively. Electrochemical techniques give access to low energy consuming devices with good sensitivity and selectivity in combination with good repeatability and low concentration detection [7]. Much research has been focused on electrochemical $\mathrm{SO}_{2}$ sensors for industrial usage $[8,9]$. The electroanalysis of sulfites (including $\mathrm{SO}_{2}$ ) using lowcost devices has recently been the focus of various research papers [10-13]. One type of electrochemical sensor is an amperometric gas sensor, containing three electrodes in contact with a liquid electrolyte; there are several amperometric sensors available commercially for $\mathrm{SO}_{2}$ detection [14]. However, the drawback of these sensors, which are typically based on aqueous electrolytes, is their short lifetime in extreme conditions such as high temperatures, causing evaporation of the solvent. Therefore, research has been focussed towards replacing conventional solvents with room temperature ionic liquids (RTILs) in amperometric gas sensor devices [15]. RTILs are a class of non-volatile, chemically and thermally stable electrolytes with high conductivity and wide electrochemical windows [15-18]. They typically consist of bulky cations and anions that result in melting points well below $100{ }^{\circ} \mathrm{C}$ and most commonly below room temperature and are highly tuneable $[19,20]$. A variety of gases, including $\mathrm{O}_{2}[21,22]$ and toxic gases such as $\mathrm{NO}_{2}[23]$ or $\mathrm{H}_{2} \mathrm{~S}$ [24], have already been studied in RTILs. Hussain et al. for example showed that sub-parts-per-million (subppm) concentration detection of ammonia gas in room temperature ionic liquids is possible with low-cost thin-film electrodes (TFEs) or microarray thin-film electrodes (MATFEs) [25].

The electrochemical reduction mechanism of sulfur dioxide at saturated concentrations has been studied in different ionic liquids on a platinum microdisk electrode $(10 \mu \mathrm{m}$ diameter) by Barrosse-Antle et al. [26], and is believed to proceed by the following reactions:

$$
\begin{aligned}
\mathrm{SO}_{2}+e^{-} & \rightleftarrows \mathrm{SO}_{2}^{{ }^{-}} \\
\mathrm{SO}_{2}{ }^{-} & \rightleftarrows \mathrm{SO}_{2}+e^{-} \\
\mathrm{SO}_{2}^{\bullet-} \cdots \text { solvent } & \rightleftarrows \mathrm{SO}_{2}+e^{-} \\
2 \mathrm{SO}_{2}{ }^{--} & \rightleftarrows \mathrm{S}_{2} \mathrm{O}_{4}{ }^{{ }^{-}}
\end{aligned}
$$




$$
\begin{aligned}
\mathrm{S}_{2} \mathrm{O}_{4}^{2^{-}} & \rightleftarrows 2 \mathrm{SO}_{2}+2 e^{-} \\
\mathrm{S}_{2} \mathrm{O}_{4}{ }^{2^{-}} \cdots \text { solvent } & \rightleftarrows 2 \mathrm{SO}_{2}+2 e^{-}
\end{aligned}
$$

It was suggested (also by other groups) [27-29] that the mechanism follows a one-electron reduction of $\mathrm{SO}_{2}$ to the $\mathrm{SO}_{2}{ }^{\circ-}$ radical anion (eq. 1). There are two to four oxidative back peaks consistently reported, but their assignment is however still inconsistent in literature. Therefore, Barrosse-Antle et al. performed a more detailed mechanistic study where it was proposed that the two main oxidation peaks are caused by the oxidation of non-solvated (eq. 2) and solvated $\mathrm{SO}_{2}{ }^{\circ-}$ (eq. 3), and the other two were from dimers formed after dimerization of the radicals (ep. 4), i.e. the non-solvated and solvated dimerised dithionite, $\mathrm{S}_{2} \mathrm{O}_{4}{ }^{2-}$ (eq. 5 and 6) [26]. Choi et al. investigated the stabilizing effect of the acidic proton of the imidazolium ring which could cause the separation of the oxidative back peaks into solvated and non-solvated processes [30]. Huang et al. also established a calibration curve between 2 and $100 \%$ of $\mathrm{SO}_{2}$ in $\left[\mathrm{C}_{4} \mathrm{mim}\right]\left[\mathrm{PF}_{6}\right]$ that resulted in a curved relationship due to a significant increase in the diffusion coefficient with increasing sulfur dioxide concentration [31]. The increased diffusion coefficients could be due to the fact that $\mathrm{SO}_{2}$ solubilities are extremely high and the gas acts as a lubricant in conventional ionic liquids, as concluded by Ren et al. [32].

In this study, we investigate the electrochemical $\mathrm{SO}_{2}$ response on thin-film electrodes for the first time. Six diverse RTILs and different thin-film electrodes will demonstrate that the ionic liquid structure as well as the choice of the electrode surface has a great influence on the electrochemical sensing behaviour. We also show the sustained detection of sulfur dioxide at the permissible exposure limit (PEL) of $2 \mathrm{ppm}$ by employing these miniaturized, low-cost and commercially available electrode devices using very small RTIL volumes. Based on our results, the next step towards commercial $\mathrm{SO}_{2}$ sensors based on room temperature ionic liquid electrolytes for detection of low ppm concentrations in real world environments may be realized.

\section{Experimental}

\subsection{Chemical reagents}

All RTILs were purchased at the highest purity possible. Diethylmethylsulfonium bis(trifluoromethylsulfonyl)imide $\left(\left[\mathrm{S}_{2,2,1}\right]\left[\mathrm{NTf}_{2}\right], \quad 99 \%\right.$, IoLiTec-Ionic Liquids Technologies GmbH, Heilbronn, Germany), 1-butyl-1methylpyrrolidinium bis(trifluoromethylsulfonium)imide $\quad\left(\left[\mathrm{C}_{4} \mathrm{mpyrr}_{[}\right]\left[\mathrm{NTf}_{2}\right], \quad 99.5 \%, \quad\right.$ IoLiTec), 1-ethyl-3methylimidazolium bis(trifluoromethylsulfonyl)imide $\quad\left(\left[\mathrm{C}_{2} \mathrm{mim}\right]\left[\mathrm{NTf}_{2}\right], \quad 99.5 \%, \quad\right.$ IoLiTec $), \quad$ 1-butyl-3methylimidazolium bis(trifluoromethylsulfonyl)imide $\quad\left(\left[\mathrm{C}_{4} \operatorname{mim}\right]\left[\mathrm{NTf}_{2}\right], \quad 99.5 \%, \quad\right.$ IoLiTec $), \quad$ 1-butyl-3methylimidazolium tetrafluoroborate $\left(\left[\mathrm{C}_{4} \mathrm{mim}\right]\left[\mathrm{BF}_{4}\right], 99 \%\right.$, IoLiTec $)$, and 1-butyl-3-methylimidazolium tris(pentafluoroethyl)trifluorophosphate ([C 4 mim] $[\mathrm{FAP}]$, high purity $>99 \%$, Merck Pty. Ltd. Kilsyth, Victoria, Australia), were used as received. Trihexyltetradecylphosphonium bis(trifluoromethylsulfonyl)imide $\left(\left[\mathrm{P}_{14,6,6,6}\right]\left[\mathrm{NTf}_{2}\right]\right)$ was kindly donated by the group of Professor Chris Hardacre, now at the University of Manchester, UK. The chemical structures of the ionic liquid cations and anions used in this study are shown in Figure 1. Acetone (CHROMASOLV®, for HPLC, $\geq 99.0 \%$, Sigma-Aldrich) and acetonitrile (anhydrous, 99.8\%, Sigma-Aldrich, Missouri, United States) were used as received. A $0.5 \mathrm{M}$ stock solution of $\mathrm{H}_{2} \mathrm{SO}_{4}$ (aq) (prepared with ultrapure water from a 95-98 wt $\% \mathrm{H}_{2} \mathrm{SO}_{4}$ solution, Ajax Finechem, WA, Australia) was used for activation of the thin-film electrodes. Sulfur dioxide (509 ppm in nitrogen) and high purity nitrogen gas (>99.999\%) were purchased from Coregas (NSW, Australia). 


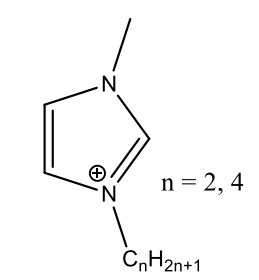

$\left[\mathrm{C}_{\mathrm{n}} \mathrm{mim}\right]^{+}$

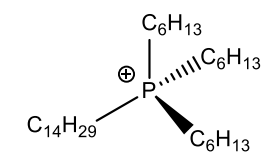

$\left[\mathrm{P}_{14,6,6,6}\right]^{+}$

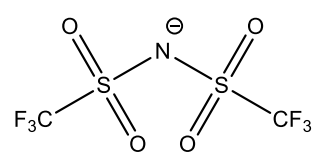

$\left[\mathrm{NTf}_{2}\right]^{-}$

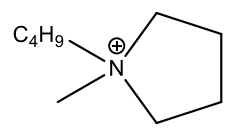

$\left[\mathrm{C}_{4} \text { mpyrr }\right]^{+}$

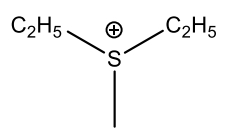

$\left[\mathrm{S}_{2,2,1}\right]^{+}$

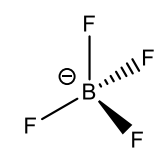

$\left[\mathrm{BF}_{4}\right]^{-}$

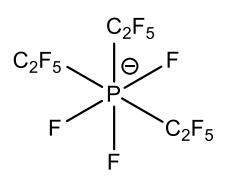

$[\mathrm{FAP}]^{-}$

Figure 1. Room temperature ionic liquid cation and anion structures used for this study.

\subsection{Electrochemical experiments}

All experiments were performed with a PGSTAT101 Autolab potentiostat (Metrohm Autolab, Gladesville, NSW, Australia) interfaced to a computer with NOVA 1.11 software. The electrochemical cell was housed inside an aluminium Faraday cage to reduce electromagnetic interferences. The working electrode (WE), counter electrode (CE) and reference electrode (RE) of the macro thin-film electrodes (TFEs) (ED-SE1, MicruX Technologies, Oviedo, Spain) are composed of either platinum (Pt) or gold $(\mathrm{Au})$ deposited on a Pyrex substrate, with a WE disk diameter of $1 \mathrm{~mm}$. Furthermore, platinum microarray thin-film electrodes (MATFEs) (ED-mSE-10-Pt, MicruX Technologies, Oviedo, Spain) were also employed as sensing devices. For MATFEs, the $1 \mathrm{~mm}$ diameter Pt disk is covered with a layer of SU8 resin, into which 91 micro-holes ( $\mu$-holes) of $10 \mu \mathrm{m}$ diameter were made to create 91 recessed microdisk electrodes. The center-to-center distance between each $\mu$-hole is $100 \pm 1 \mu \mathrm{m}$ and the SU-8 layer has a depth of $3.5 \pm 1.0 \mu \mathrm{m}$, according to the manufacturer. Photos and images of the electrode devices are given in the supporting information in Figure S1a. An electrode adapter supplied by MicruX was employed to connect the electrodes to the potentiostat. The Pt-WE was electrochemically activated prior to each experiment by cyclic voltammetry (CV) cycling ( 100 times) at $1 \mathrm{~V} \mathrm{~s}^{-1}$ in nitrogen purged $0.5 \mathrm{M} \mathrm{H}_{2} \mathrm{SO}_{4}(\mathrm{aq})$ between $-0.75 \mathrm{~V}$ and $+0.70 \mathrm{~V}$. For the Au-WE, CV cycles between $-1.2 \mathrm{~V}$ and $1.1 \mathrm{~V}$ were performed. The activated electrodes were then rinsed twice with ultrapure water and acetone before drying under a nitrogen stream. $0.5 \mu \mathrm{L}$ of the ionic liquid was drop-cast to cover all three electrodes on the TFE or MATFE (see Fig. S1b). The low volume of electrolyte on the small chip ensures relatively fast response times, whilst also keeping the cost of the sensor as low as possible, noting that RTILs themselves are relatively expensive if used in large quantities. For all measurements, the integrated CE and RE, i.e. Pt or Au, were used. The prepared electrode was then inserted into the glass T-cell supported by a silicon-bung, which is then purged with nitrogen for approximately 
$30 \mathrm{~min}$ to remove dissolved gases and impurities (such as oxygen and carbon dioxide) and monitored electrochemically until a constant blank $\mathrm{CV}$ was obtained, before commencing with the $\mathrm{SO}_{2}$ experiments. To obtain different concentrations of $\mathrm{SO}_{2}$, the $509 \mathrm{ppm}$ sulfur dioxide cylinder (nitrogen fill) was diluted with nitrogen using a gas mixing system, by adjusting relative flow rates, according to our previous work [33]. A sketch of the gas sensing set-up is shown in Fig. S1c. For the sensing experiments at $1-10 \mathrm{ppm}$, the overall flow rate is increased to $1000 \mathrm{~mL} \mathrm{~min}^{-1}$ to obtain the lowest concentrations in this study.

For long-term chronoamperometry (LTCA) experiments, the initially potential was held at $0 \mathrm{~V}$ for $5 \mathrm{~s}$ for stabilization, before stepping to an overpotential potential where $\mathrm{SO}_{2}$ reduction occurs. The system is initially placed under nitrogen to record a stable blank transient, before the analyte gas is subsequently introduced at defined concentrations, i.e. either 2 ppm or different $\mathrm{SO}_{2}$ concentrations from 1-10 ppm.

\subsection{Electrode imaging}

Scanning electron microscopy (SEM) and energy dispersive X-ray spectroscopy (EDS) (Clara-FESEM, Tescan, Kohoutovic, Czech Republic) was used to analyse the working electrodes of Pt-TFEs and Pt-MATFEs after the $\mathrm{SO}_{2}$ reduction experiments have been carried out, as well as on the control samples, which were prepared by subjecting to the same electrochemical parameters, but in the absence of $\mathrm{SO}_{2}$ gas. The SEM/EDS measurements were all carried out using an accelerating voltage of $10 \mathrm{keV}$ at a working distance of $15 \mathrm{~mm}$.

The SEM/EDS samples were consistently prepared by either performing cyclic voltammetry calibration of $\mathrm{SO}_{2}$ gas from 10 to 200 ppm on MATFEs or first performing two CV scans on freshly activated Pt-TFEs to verify the position of the $\mathrm{SO}_{2}$ peak, before holding the potential at the $\mathrm{SO}_{2}$ reduction overpotential for five minutes. The prepared electrodes were then gently soaked for 3 mins, consecutively in 3 separate vials containing clean acetonitrile, before drying under a gentle stream of dry air. The samples were then coated with $\sim 3 \mathrm{~nm}$ of platinum via vapour deposition to prevent surface charging during imaging.

\section{Results and discussion}

\subsection{Reduction of $\mathrm{SO}_{2}$ on macro thin-film electrodes}

In order to detect $\mathrm{SO}_{2}$ gas favourably at low parts-per-million (ppm) concentrations, it is important to select the optimum ionic liquid structure and electrode device that gives stable and reproducible responses. Six common RTILs with different cations and anions were used to screen their suitability for detecting low ppm concentrations of the analyte. Plots of reduction peak current vs. the square root of scan rate were linear in all RTILs, suggesting that the process is diffusion controlled (plots not shown). Figure 2 shows typical cyclic voltammetry (CV) responses for the reduction of sulfur dioxide at a scan rate of $100 \mathrm{mV} \mathrm{s}^{-1}$ in the six ionic liquids on a platinum macro thin-film electrode (Pt-TFE). The measured currents were converted into current densities $(J)$ using the geometrical surface area of the working disk (diameter of $1 \mathrm{~mm}$ ) to easily compare with the response on microarrays (see section 3.2). Background subtracted calibration curves (shown as insets in Fig. 2) were extracted from cyclic voltammetry measurements at concentrations of 10, 25, 50, 100, 150 and $200 \mathrm{ppm}$. Dashed lines represent the response in the absence of $\mathrm{SO}_{2}$. 
As reported by other researchers on conventional disk electrodes, a single $\mathrm{SO}_{2}$ reduction peak according to eq. 1 is observed in RTILs [27-29, 34, 35]. However, the number and position of the reverse oxidation peaks are strongly dependent on the scan rate as well as the solvation of the reduced species, as reported by Barrosse-Antle et al. [26]. In their study, electrochemical $\mathrm{SO}_{2}$ reduction was examined in several saturated imidazolium-based ionic liquids (100\% $\left.\mathrm{SO}_{2}\right)$, where it was revealed that four oxidative peaks can be observed in $\left[\mathrm{C}_{4} \mathrm{mim}\right]\left[\mathrm{NO}_{3}\right]$ at a fast scan rate of $4 \mathrm{~V} \mathrm{~s}^{-1}$. A comparison between experimental and simulated cyclic voltammograms resulted in the assignment of the first reverse peak to the oxidation of unsolvated $\mathrm{SO}_{2}{ }^{\bullet-}$ (eq. 2) followed by the oxidation of the solvated species (eq. 3). The acidic proton on the imidazolium cation was used as possible explanation for the solvation. Additional back-peaks belong to the oxidation of the dimer.
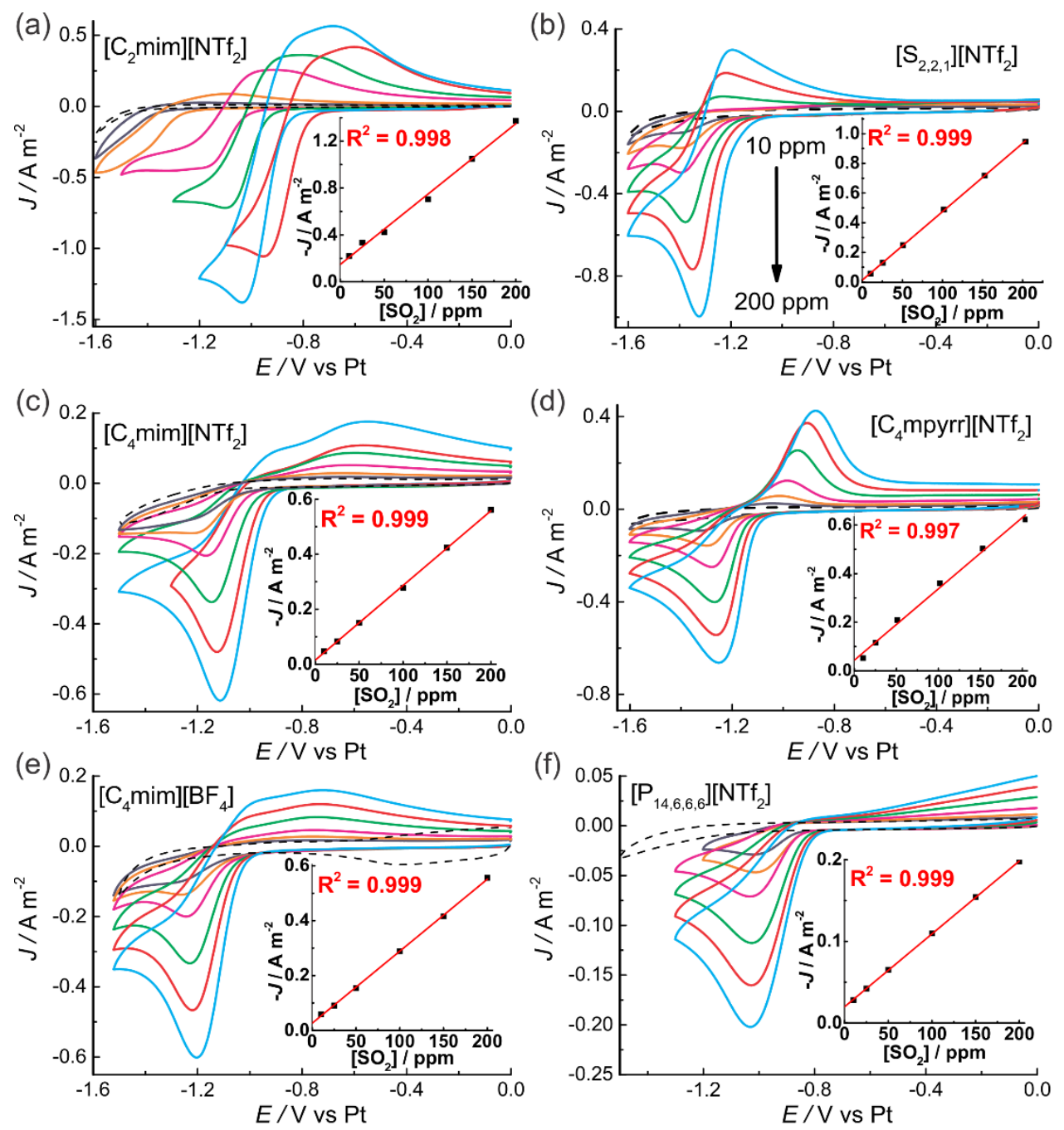

Fig. 2. Cyclic voltammetry at a scan rate of $100 \mathrm{mV} \mathrm{s}^{-1}$ for electrochemical sulfur dioxide reduction at concentrations from 10 to $200 \mathrm{ppm}$ in (a) $\left[\mathrm{C}_{2} \mathrm{mim}\right]\left[\mathrm{NTf}_{2}\right]$, (b) $\left[\mathrm{S}_{2,2,1}\right]\left[\mathrm{NTf}_{2}\right]$, (c) $\left[\mathrm{C}_{4} \mathrm{mim}\right]\left[\mathrm{NTf}_{2}\right]$, (d) $\left[\mathrm{C}_{4} \operatorname{mpyrr}\right]\left[\mathrm{NTf}_{2}\right],(\mathrm{e})\left[\mathrm{C}_{4} \mathrm{mim}\right]\left[\mathrm{BF}_{4}\right]$ and (f) $\left[\mathrm{P}_{14,6,6,6}\right]\left[\mathrm{NTf}_{2}\right]$ on a Pt-TFE (diameter $1 \mathrm{~mm}$ ) with background subtracted calibration curves shown in the insets. The dashed line represents the response in the absence of $\mathrm{SO}_{2}$.

In the present work, much lower concentrations (parts-per-million) of sulfur dioxide are studied on macro thin-film electrodes, and several different RTIL cations are employed. As shown in Fig. 2, one reduction wave was obtained in all RTILs, consistent with that by Barrosse-Antle et al. [26] In contrast to the previous study in saturated $\mathrm{SO}_{2}$ electrolytes, no third or fourth oxidation peak was observed suggesting that the dimerised products are not present. This is not unexpected due to the much lower concentrations studied in our work, leading to less chance for dimerisation. In the 
imidazolium-based ionic liquids, the presence of two oxidation back-peaks can be seen. Whereas in the sulfonium-, pyrrolidinium- and phosphonium-based ones, either one or zero anodic waves are observed. This suggests that the cation has a very large effect on the voltametric wave shapes, which is expected because the cation provides solvation of the negatively charged $\mathrm{SO}_{2}$ radical ion. Out of the non-imidazolium-based cations, the peak-to-peak separation is largest in $\left[\mathrm{C}_{4} \mathrm{mpyrr}\right]\left[\mathrm{NTf}_{2}\right]$ (Figure 2d) compared to $\left[\mathrm{S}_{2,2,1}\right]\left[\mathrm{NTf}_{2}\right]$ (Fig. 2b), with no obvious oxidative peak in $\left[\mathrm{P}_{14,6,6,6}\right]\left[\mathrm{NTf}_{2}\right]($ Fig. 2f). It is assumed that these single-centered cations are not able to solvate the radical anion effectively due to the absence of acidic protons and shielding of the cation by the hydrophobic alkyl chains.

It can also be seen in Fig. 2 that a shift in the reduction potential occurs as the concentration is changed, especially in $\left[\mathrm{C}_{2} \mathrm{mim}\right]\left[\mathrm{NTf}_{2}\right]$, which is the ionic liquid with the lowest viscosity (Table 1). For this study, the inbuilt reference electrode (RE) was used, however it has previously been demonstrated by Wandt et al. that the introduction of gas can cause a severe RE potential shift [36]. The reference potential can also be affected by the migration of electrogenerated species towards the platinum reference electrode, especially in a less viscous solvent. Out of the six different RTILs studied, the shift in $\mathrm{SO}_{2}$ reduction potential was only significant in $\left[\mathrm{C}_{2} \mathrm{mim}\right]\left[\mathrm{NTf}_{2}\right]$ (which has the lowest viscosity out of the different RITLs used) [37]. Therefore, it is concluded [ $\left.\mathrm{C}_{2} \operatorname{mim}\right]\left[\mathrm{NTf}_{2}\right]$ is not an ideal electrolyte for $\mathrm{SO}_{2}$ detection on these electrode devices. In terms of the analytical response, almost all ionic liquids show an excellent linear relationship $\left(R^{2} \approx 0.999\right)$ between current density and concentration. In contrast, Huang et al. [31] reported a curved like behavior, most likely caused by the high $\mathrm{SO}_{2}$ solubility that can act as lubricant resulting in increased diffusion coefficients.

We also studied the use of gold thin-film electrodes in four of the RTILs to determine if Au shows an improved behaviour compared to $\mathrm{Pt}$ (see cyclic voltammetry for 10-200 ppm $\mathrm{SO}_{2}$ on gold electrodes in Fig. S2). Similar trends as on Pt can be observed with a single reduction peak and the reduction potential shifting in $\left[\mathrm{C}_{2} \mathrm{mim}\right]\left[\mathrm{NTf}_{2}\right]$. In terms of the oxidative back-peaks, the reverse peaks appear to be sharper and well defined on gold; specifically the imidazoliumbased RTILs show a more pronounced first oxidation peak and for [ $\left.\mathrm{C}_{4} \mathrm{mpyrr}\right]\left[\mathrm{NTf}_{2}\right]$, two oxidation waves are observed in contrast to a single one on platinum. However, the behaviour in $\left[\mathrm{P}_{14,6,6,6}\right]\left[\mathrm{NTf}_{2}\right]$, is much better on Pt compared to Au, where an obvious reduction peak is not observed on Au. Linear calibration curves were obtained for all samples on gold electrodes (Fig. S2), with the exception of $\left[\mathrm{P}_{14,6,6,6}\right]\left[\mathrm{NTf}_{2}\right]$. According to the literature [38], the adsorption strength of $\mathrm{SO}_{2}$ is markedly different between platinum and gold surfaces, which may affect the sensing response, especially in the presence of the large tetraalkylphosphonium cation which structures at the negatively charged electrode surface.

In Table 1, the slopes of the calibration plots on the Pt-TFE and the Pt-MATFE (discussed in section 3.2), are summarized in order of increasing RTIL viscosity. The viscosities cover a broad range from $39.7 \mathrm{mPa}$ for $\left[\mathrm{C}_{2} \mathrm{mim}\right]\left[\mathrm{NTf}_{2}\right]$ to $453.6 \mathrm{mPa}$ s for $\left[\mathrm{P}_{14,6,6,6}\right]\left[\mathrm{NTf}_{2}\right]$. The sensitivity - defined as the slope of the calibration curve - is the highest in $\left[\mathrm{C}_{2} \mathrm{mim}\right]\left[\mathrm{NTf}_{2}\right]$, approximately six times higher than the lowest sensitivity in $\left[\mathrm{P}_{14,6,6,6}\right]\left[\mathrm{NTf}_{2}\right]$. The sensitivity decreases with increasing viscosity, suggesting that a lower viscosity of the electrolyte is desired for higher sensitivity detection of analytes.

The lowest concentrations of sulfur dioxide detected in the existing literature are well below $10 \mathrm{ppm}$, but all employ modified electrodes at high temperatures, and different electrochemical techniques (i.e. not amperometric). Betty et al. reported the detection of $1 \mathrm{ppm} \mathrm{SO}$ at room temperature with synthesized $\mathrm{SnO}_{2}$ nanoparticle films via DC conductance 
and $\mathrm{AC}$ impedance [39]. Zhou et al. were able to electrochemically detect $3 \mathrm{ppm}$ of $\mathrm{SO}_{2}$ on $\mathrm{NiO}-\mathrm{ZnO}$ nanodisks at $240{ }^{\circ} \mathrm{C}$ [40]. And Liu et al. reported the detection of $0.5 \mathrm{ppm}$ on Au-modified $\mathrm{SnO}_{2}$ at $200{ }^{\circ} \mathrm{C}$ [41]. Based on our results, the combination of commercially available room temperature ionic liquids and low-cost Pt-TFEs are a good option for sensing low concentrations of $\mathrm{SO}_{2}$ gas using amperometric techniques at ambient temperatures without high power consumption. The $10 \mathrm{ppm} \mathrm{CV}$ response is clearly distinguishable from the blank measurement and suggests that much lower analyte concentrations can be easily detected, as will be described in more detail later.

Table 1. Summary of viscosities $(\eta)$ at $293 \mathrm{~K}$ and sensitivities for $10-200 \mathrm{ppm} \mathrm{SO}_{2}$ on a Pt-TFE and a Pt-MATFE in six different ionic liquids.

\begin{tabular}{|c|c|c|c|}
\hline RTIL & $\eta / \mathrm{mPa} s$ & $\begin{array}{c}\text { Pt-TFE } \\
\text { slope / } \\
\text { mA } \mathbf{~ m}^{-2} \mathbf{p p m}^{-1}\end{array}$ & $\begin{array}{c}\text { Pt-MATFE } \\
\text { slope / } \\
\text { mA } \mathbf{~ m}^{-2} \mathbf{p p m}^{-1}\end{array}$ \\
\hline$\left[\mathrm{C}_{2} \operatorname{mim}\right]\left[\mathrm{NTf}_{2}\right]$ & $39.7[42]$ & 6.0 & 7.3 \\
\hline$\left[\mathrm{S}_{2,2,1}\right]\left[\mathrm{NTf}_{2}\right]$ & $49.9[43]$ & 4.6 & 10.1 \\
\hline$\left.\left[\mathrm{C}_{4} \mathrm{mim}\right]\left[\mathrm{NTf}_{2}\right]\right]$ & $66.4[44]$ & 2.7 & 4.6 \\
\hline$\left[\mathrm{C}_{4} \mathrm{mpyrr}\right]\left[\mathrm{NTf}_{2}\right]$ & $98.7[45]$ & 2.9 & 7.7 \\
\hline$\left[\mathrm{C}_{4} \mathrm{mim}\right]\left[\mathrm{BF}_{4}\right]$ & $135.6[46]$ & 2.6 & 1.4 \\
\hline$\left[\mathrm{P}_{14,6,6,6}\right]\left[\mathrm{NTf}_{2}\right]$ & $453.6[47]$ & 0.89 & 0.38 \\
\hline
\end{tabular}

\subsection{Reduction of $\mathrm{SO}_{2}$ on platinum microarray thin-film electrodes}

Microelectrodes give rise to higher current densities due to the dominance of radial diffusion. Although the overall current is lower at microelectrodes, this can be compensated for by including multiple electrodes in an array. Microarray thin-film electrodes (MATFEs) are commercially available, such as those from MicruX used in this study, which have a design with 91 recessed microelectrodes having $10 \mu \mathrm{m}$ diameter. Hussain et al. already demonstrated the improved sensing behaviour of MATFEs over macro thin-film electrodes (TFEs), resulting in the detection of sub-ppm concentrations of ammonia gas [25]. We therefore studied $\mathrm{SO}_{2}$ reduction on Pt-MATFEs to compare current densities and sensitivities with a view to detect ultra-low concentrations of the gas. Fig. 3 shows typical cyclic voltammetry responses for the reduction of sulfur dioxide at a scan rate of $100 \mathrm{mV} \mathrm{s}^{-1}$ in six ionic liquids on platinum microarray thin-film electrodes (Pt-MATFEs). The measured currents were converted into current densities $(J)$ using the geometrical surface area of the working electrodes ( $10 \mu \mathrm{m}$ diameter per electrode multiplied by 91 electrodes), for direct comparison with the macro TFEs. Background subtracted calibration plots are shown as insets and the dashed lines show the response in the absence of the analyte.

In contrast to the peak-shaped behaviour observed on macro TFEs, MATFEs show steady state or slanted steady state behaviour due to the microelectrode-like nature and dominance of radial diffusion. The slanted response is thought to be caused by background impurities in the RTILs that superimpose the steady state current as can be seen in the blank CVs (Fig. 3). At such low gas concentrations, any small impurity peak can have a significant effect on the analyte current. This is especially apparent in the imidazolium RTILs (Fig. 3a, c and e), where it has been reported that impurities

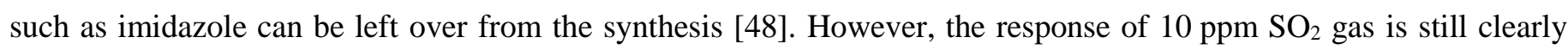
distinguishable from the blank and a highly linear relationship $\left(R^{2} \approx 0.999\right)$ between $\mathrm{SO}_{2}$ concentration and $J$ is observed 
in all electrolytes. As expected, the current densities are higher on microarray electrodes for most of the samples. Both, $\left[\mathrm{S}_{2,2,1}\right]\left[\mathrm{NTf}_{2}\right]$ as well as $\left[\mathrm{C}_{4}\right.$ mpyrr] $\left[\mathrm{NTf}_{2}\right]$ give current densities more than twice as high on the MATFEs compared to macro TFEs. Whereas, for the two more viscous RTILs, i.e. $\left[\mathrm{C}_{4} \mathrm{mim}\right]\left[\mathrm{BF}_{4}\right]$ and $\left[\mathrm{P}_{14,6,6,6}\right]\left[\mathrm{NTf}_{2}\right], J$ is approximately half on the MATFE compared to the TFE. This could perhaps be the result of significant build up $\mathrm{SO}_{2}$ reduction products, trapped in the microholes of the MATFEs (see discussion in section 3.2), leading to a slowing of the reaction kinetics according to Le Chatelier's principle; compared to the macro TFE, where reduction products have more space to diffuse away rather than accumulate at the working electrode. It is also worth mentioning the flatter blank response in $\left[\mathrm{S}_{2,2,1}\right]\left[\mathrm{NTf}_{2}\right]$ and $\left[\mathrm{C}_{4}\right.$ mpyrr $]\left[\mathrm{NTf}_{2}\right]$ in the potential range for $\mathrm{SO}_{2}$ reduction, which is more ideal for sensing lower concentrations of the gas.
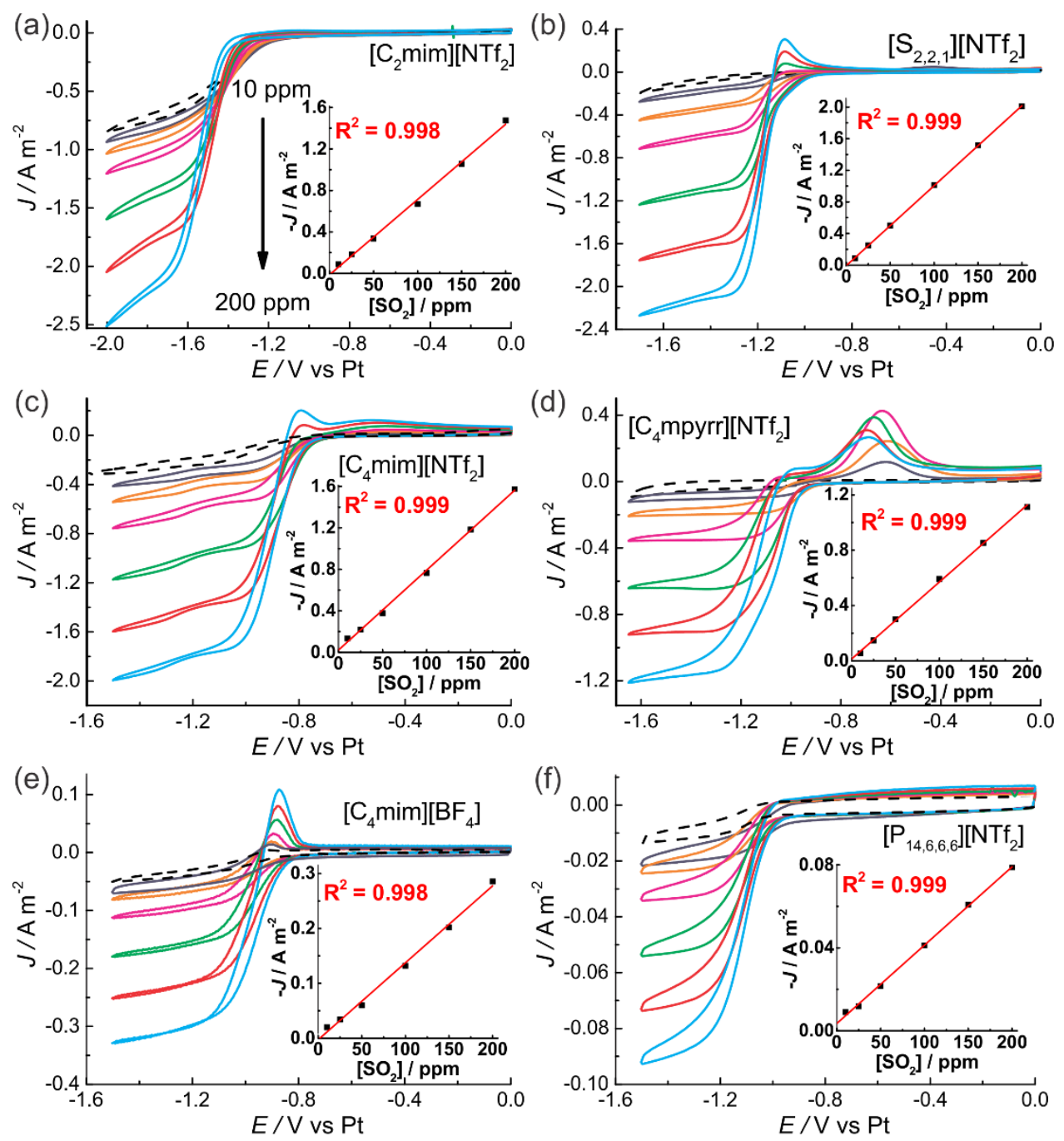

Fig. 3. Cyclic voltammetry at a scan rate of $100 \mathrm{mV} \mathrm{s}^{-1}$ for electrochemical sulfur dioxide reduction at concentrations between 10 and $200 \mathrm{ppm}$ in (a) $\left[\mathrm{C}_{2} \mathrm{mim}\right]\left[\mathrm{NTf}_{2}\right]$, (b) $\left[\mathrm{S}_{2,2,1}\right]\left[\mathrm{NTf}_{2}\right]$, (c) $\left[\mathrm{C}_{4} \mathrm{mim}\right]\left[\mathrm{NTf}_{2}\right]$, (d) $\left[\mathrm{C}_{4} \mathrm{mpyrr}\right]\left[\mathrm{NTf}_{2}\right]$, (e) $\left[\mathrm{C}_{4} \mathrm{mim}\right]\left[\mathrm{BF}_{4}\right]$ and (f) $\left[\mathrm{P}_{14,6,6,6}\right]\left[\mathrm{NTf}_{2}\right]$ on a Pt-MATFE with background subtracted calibration curves shown in the insets. The dashed line represents the response in the absence of $\mathrm{SO}_{2}$.

A comparison of the slopes (sensitivities) of the calibration plots of the macro TFEs and MATFEs is shown in Table 1, revealing significantly higher sensitivities (2.2-2.6 times) for the microarrays, with values of 10.1 and $7.7 \mathrm{~mA} \mathrm{~m}^{-2} \mathrm{ppm}^{-}$ ${ }^{1}$ for $\left[\mathrm{S}_{2,2,1}\right]\left[\mathrm{NTf}_{2}\right]$ and $\left[\mathrm{C}_{4} \mathrm{mpyrr}\right]\left[\mathrm{NTf}_{2}\right]$, respectively. The most viscous RTILs have the smallest slopes, and interestingly, they even show lower sensitivities on the microarray thin-film electrode compared to the macro TFE. The improvement in the sensitivity by more than a factor of two for the sulfonium- and the pyrrolidinium-based ionic liquids, 
in addition to their flatter blank response, appear to be good characteristics for further studies at ultra-low ppm concentrations of $\mathrm{SO}_{2}$.

\subsection{Sulfur deposition after $\mathrm{SO}_{2}$ reduction experiments}

Fig. 4a shows a scanning electron microscope (SEM) image of a microhole on a Pt-MATFE after cyclic voltammetry experiments from 10 to $200 \mathrm{ppm} \mathrm{SO} \mathrm{S}_{2}$ were performed in $\left[\mathrm{C}_{4} \mathrm{mpyrr}\right]\left[\mathrm{NTf}_{2}\right]$. The particles deposited within the microhole were verified as sulfur (S) as shown in Fig. $4 \mathrm{~b}$ on the grey marked area (1). The blue area (2) was chosen on a cleaner area within the microhole showing a large Pt peak and a subtle sulfur peak, and finally (3) was measured on the surrounding SU-8 layer showing the absence of both Pt and S peaks. The silicon ( $\mathrm{Si}$ ) peak is from the underlying glass substrate of the Pt-MATFE due to penetration of the electron beam - which also makes the EDS measurement of thinner sulfur contaminants and particles more challenging (see Fig. S4). Similar sulfur deposits were found in the microholes of Pt-MATFEs after $\mathrm{SO}_{2}$ reduction in the RTIL $\left[\mathrm{S}_{2,2,1}\right]\left[\mathrm{NTf}_{2}\right]$ (results not shown). The electrochemical reduction of $\mathrm{SO}_{2}$ in aqueous solutions produces sulfur according to the following mechanism [38]:

$$
\mathrm{SO}_{2}(\mathrm{aq})+4 \mathrm{H}^{+}+4 e^{-} \rightarrow \mathrm{S}(\mathrm{s})+2 \mathrm{H}_{2} \mathrm{O}
$$

To the best of our knowledge, the electrochemical reduction of $\mathrm{SO}_{2}$ to sulfur in aprotic ionic liquids has previously not been observed in the literature. However, it is well known that trace concentrations of water persist in ionic liquids even after purging under high vacuum [49-51]. This could cause the reaction in equation (7) to occur even in aprotic RTILs, resulting in the formation of sulfur particles on the platinum electrode surface.
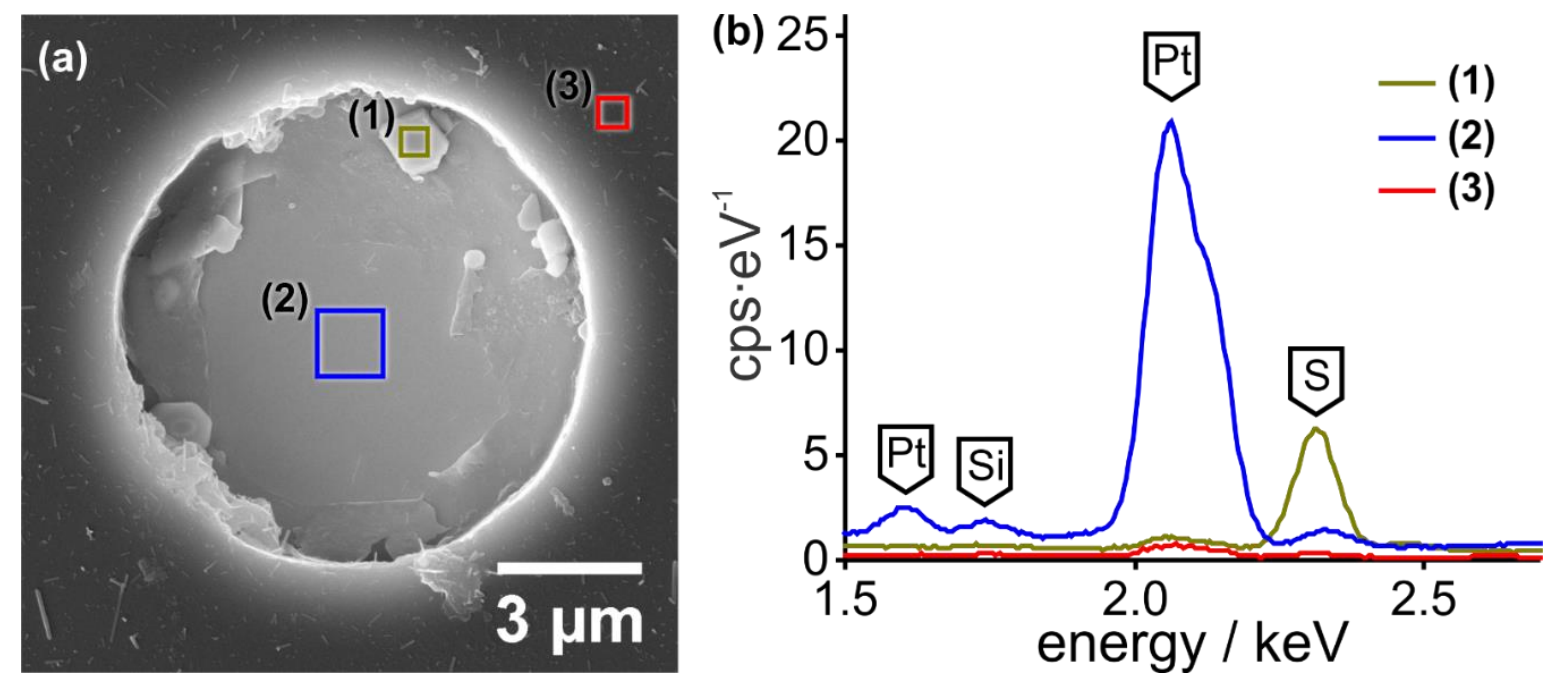

Fig. 4. (a) SEM image of a Pt-MATFE microhole after carrying out cyclic voltammetry calibration experiments in [ $\left.\mathrm{C}_{4} \mathrm{mpyrr} \mathrm{NNTf}_{2}\right]$ (as shown in Fig. 3d). (b) EDS spectra measured on three different areas as marked in the SEM image in Fig. (a).

Long-term chronoamperometry (LTCA) experiments were carried out at the $\mathrm{SO}_{2}$ reduction overpotential in the presence of $200 \mathrm{ppm} \mathrm{SO} \mathrm{S}_{2}$ in $\left[\mathrm{C}_{4}\right.$ mpyrr] $\left[\mathrm{NTf}_{2}\right]$ and $\left[\mathrm{C}_{4} \mathrm{mim}\right]\left[\mathrm{NTf}_{2}\right]$, as well as in $\left[\mathrm{C}_{4} \mathrm{mim}\right][\mathrm{FAP}]$ (a non-sulfur containing ionic liquid) on macro-sized Pt-TFEs, where no microholes are present. All experiments show that the surface is populated with tiny particulates of sulfur deposits (see Fig. S3a) after $\mathrm{SO}_{2}$ reduction experiments. A few larger deposits were also observed near the edge of the macro working electrode of the Pt-TFE - likely due to higher flux at the edges, similar to the case of the MATFEs. However, carrying out the exact same LTCA measurements in the absence of $\mathrm{SO}_{2}$ gas resulted 
in a clean Pt-TFE surface as shown in Fig. S3b, showing that it is the $\mathrm{SO}_{2}$ reduction process that is responsible for the presence of the deposits.

It is known that the electrochemical oxidation performance of $\mathrm{SO}_{2}$ on Pt electrodes in aqueous media is intrinsically linked to sulfur formation at the electrode surface at reducing potentials [38]. In other words, the presence of sulfur on the working electrode acts as a catalyst for $\mathrm{SO}_{2}$ oxidation in aqueous solvents. However, the impact of sulfur deposits towards $\mathrm{SO}_{2}$ reduction in aprotic RTILs has not yet been reported in the literature. To compare the impact of sulfur deposition on $\mathrm{SO}_{2}$ reduction on both TFEs and MATFEs, and to investigate the suitability of our sensors for continuous monitoring of $\mathrm{SO}_{2}$ gas (even with the possibility of electrode fouling), we proceeded with further amperometric studies on both TFEs and MATFEs in the two selected RTILs, $\left[\mathrm{C}_{4}\right.$ mpyrr $]\left[\mathrm{NTf}_{2}\right]$ and $\left[\mathrm{S}_{2,2,1}\right]\left[\mathrm{NTf}_{2}\right]$. To reduce the significance of sulfur build-up on the working electrode, as well as to study the low concentration analytical utility of these devices for $\mathrm{SO}_{2}$ sensing, a lower $\mathrm{SO}_{2}$ concentration range (1-10 ppm) was chosen, as discussed in the next section.

\subsection{Detection of low parts-per-million concentrations of $\mathrm{SO}_{2}$}

The permissible exposure limit (PEL) for sulfur dioxide gas is $2 \mathrm{ppm}$, averaged over a 10-hour working shift, according to the National Institute for Occupational Safety and Health (NIOSH). The reliable and fast detection of concentrations well below $10 \mathrm{ppm}$ is therefore a focus in $\mathrm{SO}_{2}$ sensing research to avoid harmful effects on human health. Due to the higher current density, Pt-MATFEs were initially selected as the most ideal surface to carry out low concentration detection of sulfur dioxide. The RTILs $\left[\mathrm{S}_{2,2,1}\right]\left[\mathrm{NTf}_{2}\right]$ and $\left[\mathrm{C}_{4}\right.$ mpyrr $]\left[\mathrm{NTf}_{2}\right]$ were chosen because they showed the highest sensitivity in combination with very clean responses in the absence of $\mathrm{SO}_{2}$ (see Fig. 3). Additionally, the relatively low viscosities of these RTILs are a desired characteristic for faster response times.

Fig. S5 and S6 in the supporting information show CVs for 1-10 ppm SO $\mathrm{S}_{2}$ in $\left[\mathrm{S}_{2,2,1}\right]\left[\mathrm{NTf}_{2}\right]$ and $\left[\mathrm{C}_{4} \mathrm{mpyrr}\right]\left[\mathrm{NTf}_{2}\right]$ on PtMATFEs, which were the most promising systems at higher concentrations. CV measurements showed a linear relationship ( $R^{2}=0.996$ and 0.999 , respectively) between current density and concentration. However, long-term chronoamperometry (LTCA) revealed unstable currents during the continuous monitoring of $\mathrm{SO}_{2}$. A more detailed discussion can be found in the supporting information. The instability is attributed to the electrode surface being fouled by sulfur deposits during the electrochemical reduction of $\mathrm{SO}_{2}$, as discussed previously. Therefore, instead of acting as catalysts (as was the case for aqueous $\mathrm{SO}_{2}$ oxidation) [38], the sulfur deposits act as a passivant for the reduction process in RTILs. Furthermore, the recessed electrodes lead to accumulation of reduction products, which in turn could lead to complete sulfur passivation of the microelectrodes within the array. The harsh constant biasing LTCA technique is therefore not suitable for $\mathrm{SO}_{2}$ sensing on MATFEs that have recessed electrode designs.

In light of this, we employed mm-sized (macro) Pt-TFEs for low concentration $(<10 \mathrm{ppm}) \mathrm{SO}_{2}$ sensing. Of the two RTILs, $\left[\mathrm{C}_{4}\right.$ mpyrr] $\left[\mathrm{NTf}_{2}\right]$ was singled out as it was substantially less impacted by the occurrence of sulfur deposition compared to $\left[\mathrm{S}_{2,2,1}\right]\left[\mathrm{NTf}_{2}\right]$. Fig. 4 a shows the $\mathrm{CV}$ response of 1-10 ppm $\mathrm{SO}_{2}$ in $\left[\mathrm{C}_{4} \mathrm{mpyrr}\right]\left[\mathrm{NTf}_{2}\right]$ on a Pt-TFE, with the blank measurement in pure nitrogen shown as the dashed line. The inset shows a calibration plot of current density vs. concentration. The shapes of the CVs at these low concentrations appear similar to that obtained at the higher (10 $200 \mathrm{ppm}$ ) concentration range (see Fig. $2 \mathrm{~d})$. A good fit $\left(R^{2}=0.998\right)$ was achieved for the calibration, however, the definition of peaks at lower concentrations is not as good as the higher concentrations, resulting in the calibration plot for CV measurements giving a limit of detection (based on three standard deviations of the line) of $1.5 \mathrm{ppm}$. 

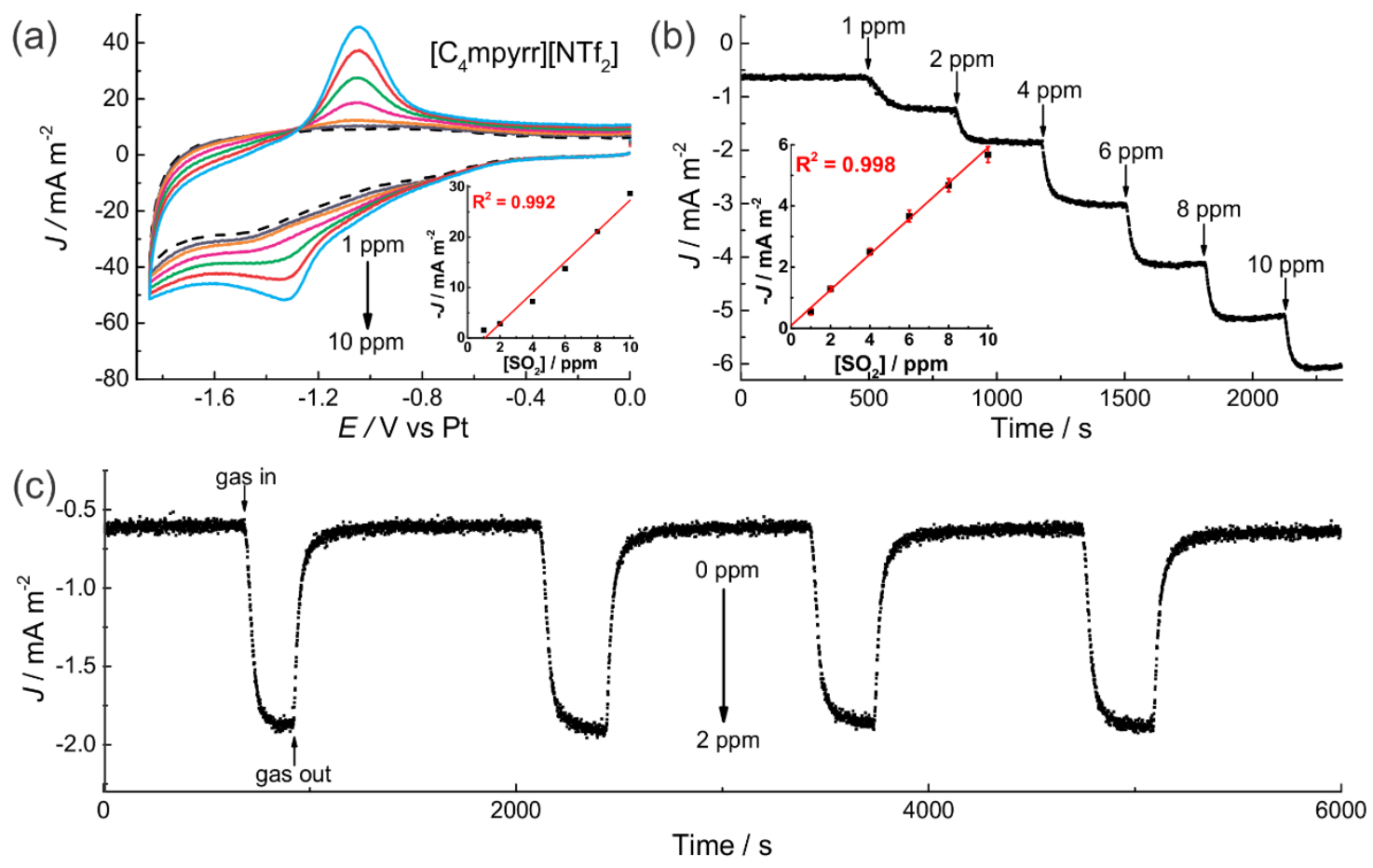

Fig. 5. (a) Cyclic voltammetry at a scan rate of $100 \mathrm{mV} \mathrm{s}^{-1}$ for electrochemical $\mathrm{SO}_{2}$ reduction at concentrations from 1 to $10 \mathrm{ppm}$ in $\left[\mathrm{C}_{4}\right.$ mpyrr $]\left[\mathrm{NTf}_{2}\right]$ on a Pt-TFE with the background subtracted calibration curve including error bars from 3 independent experiments shown in the inset. The dashed line represents the blank scan in the absence of $\mathrm{SO}_{2}$. A total flow rate of $1000 \mathrm{~mL} \mathrm{~min}^{-1} \mathrm{was}_{\mathrm{employed}}$ (b) Long-term chronoamperometry (LTCA) response for electrochemical sulfur dioxide reduction at concentrations from 1 to $10 \mathrm{ppm}$ in $\left[\mathrm{C}_{4} \mathrm{mpyrr}\right]\left[\mathrm{NTf}_{2}\right]$ on a Pt-TFE with the background subtracted calibration curve including error bars from 3 independent experiments shown in the inset. (c) Long-term chronoamperometry response for electrochemical sulfur dioxide reduction by a periodic introduction of 2 ppm $\mathrm{SO}_{2}$ (response phase) followed by a period of $\mathrm{N}_{2}$-purging (recovery phase) in $\left[\mathrm{C}_{4} \mathrm{mpyrr}\right]\left[\mathrm{NTf}_{2}\right]$ on a Pt-TFE, with a nitrogen flushing step employed between $\mathrm{SO}_{2}$ additions.

Long-term chronoamperometry (LTCA) was then performed to show if $\mathrm{SO}_{2}$ can be continuously monitored at low concentrations. The potential was held at $-1.5 \mathrm{~V}$ where sulfur dioxide is reduced, and the cell was placed under nitrogen to obtain a blank amperometric transient. $\mathrm{SO}_{2}$ at different concentrations from 1-10 ppm was then introduced, and the plateau current obtained at each ppm level was used to establish a calibration curve. Fig. 5b shows the LTCA response from 1 to $10 \mathrm{ppm}$ of $\mathrm{SO}_{2}$, with the inset calibration plot showing a highly linear relationship between $J$ and [ $\left[\mathrm{SO}_{2}\right]$. The limit of detection (LOD) was found to be $0.5 \mathrm{ppm}$ for LTCA, compared to $1.5 \mathrm{ppm}$ for CV, which suggests the preference of long-term chronoamperometry over cyclic voltammetry for reliably detecting very low $\mathrm{SO}_{2}$ concentrations. This is consistent with our previous experiments for ammonia detection, which also showed that LTCA was the preferred technique compared to CV at sub-ppm concentrations [52].

It was noticed that the plateau current on TFEs was constant for more than $180 \mathrm{~s}$, suggesting good stability with minimal effects from electrode fouling. To determine if the sensor can reliably measure at concentrations close to the permissible exposure limit, repeated additions of $2 \mathrm{ppm} \mathrm{SO}_{2}$ were performed. Fig. $5 \mathrm{c}$ shows the amperometric response for periodic introductions of $2 \mathrm{ppm} \mathrm{SO}_{2}$ (response phase) followed by a period of $\mathrm{N}_{2}$-purging (recovery phase) for four cycles. Reproducible responses and very little change in the plateau current was observed. Table 2 summarizes the sensitivity (slopes) in $\left[\mathrm{C}_{4}\right.$ mpyrr $]\left[\mathrm{NTf}_{2}\right]$ on the macro Pt-TFE obtained from the $\mathrm{CV}$ measurements for both concentration ranges, the sensitivity obtained from the LTCA calibration at 1-10 ppm of $\mathrm{SO}_{2}$ and the $t_{90}$ response and $t_{90}$ recovery time (where 
$t_{90}$ is defined as the time taken to reach $90 \%$ of the steady-state current). As can be seen, the sensitivity using CV is highly consistent and within experimental error for both concentration ranges. The response and recovery times of $91( \pm 8) \mathrm{s}$ and $103( \pm 11) \mathrm{s}$ respectively, are significantly higher compared to smaller, non-polar gases with lower solubilities, such as oxygen, which had a response time of approximately $20 \mathrm{~s}$ according to Huang et al. [21]. Although a low volume of ionic liquid was used in our study $(0.5 \mu \mathrm{L})$, it is expected that the response time could be further reduced with a thinner electrolyte layer. Based on these observations, we believe it should even be possible to reliably detect $\mathrm{SO}_{2}$ at concentrations lower than $1 \mathrm{ppm}$. This is a significant outcome, since so far, the reliable detection of such low concentrations of sulfur dioxide has not been observed in room temperature in RTILs, especially with miniaturised, lowcost electrodes.

Table 2. Electrochemical data for the reduction of $\mathrm{SO}_{2}(10-200 \mathrm{ppm})$ and $(1-10 \mathrm{ppm})$ in the RTIL $\left[\mathrm{C}_{4} \mathrm{mpyrr}\right]\left[\mathrm{NTf}_{2}\right]$, using cyclic voltammetry (CV) and long-term chronoamperometry (LTCA) on platinum thin-film electrodes (Pt-TFEs) including the slope of the calibration curves, and the $t_{90}$ response and $t_{90}$ recovery for $2 \mathrm{ppm}$ additions using LTCA.

\begin{tabular}{|c|c|c|c|c|c|}
\hline \multirow[b]{2}{*}{ RTIL } & \multicolumn{2}{|c|}{$\mathbf{C V}$} & \multirow{2}{*}{$\begin{array}{c}\text { LTCA } \\
\text { slope }(1- \\
10 \text { ppm }) \\
/ \mathbf{m A ~ m}^{-2} \mathbf{p p m}^{-1}\end{array}$} & \multicolumn{2}{|c|}{ LTCA for $2 \mathrm{ppm} \mathrm{SO}$} \\
\hline & $\begin{array}{l}\text { slope }(10-200 \text { ppm }) \\
\qquad / \mathrm{mA} \mathrm{m}^{-2} \mathbf{p p m}^{-1}\end{array}$ & $\begin{array}{l}\text { slope (1-10 ppm) } \\
\text { / mA } \mathbf{~ m}^{-2} \text { ppm }^{-1}\end{array}$ & & $\begin{array}{c}t_{90} \\
\text { response } \\
/ \mathrm{s}\end{array}$ & $\begin{array}{c}t_{90} \\
\text { recovery } \\
/ \mathrm{s}\end{array}$ \\
\hline$\left[\mathrm{C}_{4} \mathrm{mpyrr}\right]\left[\mathrm{NTf}_{2}\right]$ & $2.9( \pm 0.1)$ & $3.0( \pm 0.1)$ & $0.57( \pm 0.01)$ & $91( \pm 8)$ & $103( \pm 11)$ \\
\hline
\end{tabular}




\section{Conclusions}

The electrochemical reduction of sulfur dioxide has been studied in six different room temperature ionic liquids (RTILs) on two different electrode materials and using two different electrode geometries using cyclic voltammetry. Linear relationships between current density vs. $\mathrm{SO}_{2}$ concentrations from $10-200 \mathrm{ppm}$ were established for all systems with higher current densities on microarray electrodes compared to their macro counterparts, except in the two most viscous ionic liquids, $\left[\mathrm{C}_{4} \mathrm{mim}\right]\left[\mathrm{BF}_{4}\right]$ and $\left[\mathrm{P}_{14,6,6,6}\right]\left[\mathrm{NTf}_{2}\right]$. It was concluded that platinum electrodes outperformed gold surfaces in all RTILs. The most promising ionic liquid - $\left[\mathrm{C}_{4}\right.$ mpyrr $]\left[\mathrm{NTf}_{2}\right]$ - was then employed for further studies with a Pt-TFE and a Pt-MATFE for sensing experiments at low ppm $\mathrm{SO}_{2}$ concentrations. Linear relationships between current density $(J)$ and concentration were obtained for 1-10 ppm $\mathrm{SO}_{2}$ using both cyclic voltammetry and long-term chronoamperometry. In the case of microarray electrodes, long-term stability and reproducibility was not ideal due to fouling of the electrode surface caused by sulfur deposition in the microholes; this was verified with scanning electron microscopy in conjunction with energy dispersive spectroscopy. This is the believed to be the first observation of this phenomenon in aprotic RTILs. Sulfur deposition was not found to affect the amperometric sensing performance on the larger (macro) Pt-TFEs at ppm $\mathrm{SO}_{2}$ concentrations. Therefore, we recommend the use of low-cost macro-sized thin-film electrodes (TFEs) for the reliable detection of sulfur dioxide in RTILs at concentrations close to, and lower than, the permissible exposure limit (PEL) of 2 ppm.

\section{Acknowledgements}

This work was supported by an Australian Research Council (ARC) Future Fellowship Award (FT170100315) for DSS. The authors thank Professor Christopher Hardacre for kind donation of the RTIL [ $\left.\mathrm{P}_{14,6,6,6}\right]\left[\mathrm{NTf}_{2}\right]$ used in this work. The authors acknowledge the use of the sample preparation facility and the scanning electron microscope instrument at the Microscopy and Microanalysis Facility at John de Laeter Research Centre in Curtin University, which is partially funded by the University, State and Commonwealth Governments of Australia.

\section{Appendix A. Supplementary Data}

Photos of the thin-film electrode devices and TFE and MATFE working electrode surfaces, the sensing mechanism, and a sketch of the gas-mixing set-up and electrochemical cell. Cyclic voltammetry responses for $1-200 \mathrm{ppm}$ sulfur dioxide reduction in four different ionic liquids on gold macro thin-film electrodes, scanning electron microscope images and energy dispersive X-ray spectroscopy spectra of platinum thin-film electrodes after long-term chronoamperometry in the presence of sulfur dioxide in $\left[\mathrm{C}_{4}\right.$ mpyrr] $\left[\mathrm{NTf}_{2}\right]$, and experimental results and a short discussion on the reduction of 1-10 ppm $\mathrm{SO}_{2}$ in $\left[\mathrm{S}_{2,2,1}\right]\left[\mathrm{NTf}_{2}\right]$ and $\left[\mathrm{C}_{4} \mathrm{mpyrr}\right]\left[\mathrm{NTf}_{2}\right]$ using cyclic voltammetry and long-term chronoamperometry on platinum microarray thin-film electrodes. Supplementary data to this article can be found online at ..... 


\section{References}

[1] M.A. Bauer, M.J. Utell, P.E. Morrow, D.M. Speers, F.R. Gibb, Inhalation of 0.30 ppm Nitrogen Dioxide Potentiates Exercise-induced Bronchospasm in Asthmatics. Am. Rev. Respir. Dis. 134 (1986) 1203-1208.

[2] G.R. Carmichael, D.G. Streets, G. Calori, M. Amann, M.Z. Jacobsen, J. Hansen, H. Ueda, Changing Trends in Sulfur Emissions in Asia: Implications for Acid Deposition, Air Pollution, and Climate. Environ. Sci. Technol. 36 (2002) 4707-4713.

[3] R.R. Khan, M.J.A. Siddiqui, Review on effects of Particulates; Sulfur Dioxide and Nitrogen Dioxide on Human Health. Int. Res. J. Environment Sci. 3 (2014) 70-73.

[4] I.A. Levitsky, Porous Silicon Structures as Optical Gas Sensors. Sensors 15 (2015) 19968-19991.

[5] M. Li, E.B. Myers, H.X. Tang, S.J. Aldridge, H.C. McCaig, J.J. Whiting, R.J. Simonson, N.S. Lewis, M.L. Roukes, Nanoelectromechanical Resonator Arrays for Ultrafast, Gas-Phase Chromatographic Chemical Analysis. Nano Lett. 10 (2010) 3899-3903.

[6] J.W. Fergus, A review of electrolyte and electrode materials for high temperature electrochemical $\mathrm{CO}_{2}$ and $\mathrm{SO}_{2}$ gas sensors. Sens. Actuators B 134 (2008) 1034-1041.

[7] Z. Yunusa, M.N. Hamidon, A. Kaiser, Z. Awang, Gas Sensors: A Review. Sens. Transducers 168 (2014) 6175.

[8] A.W.E. Hodgson, P. Jacquinot, P.C. Hauser, Electrochemical Sensor for the Detection of $\mathrm{SO}_{2}$ in the Low-ppb Range. Anal. Chem. 71 (1999) 2831-2837.

[9] J.M. Skeaff, A.A. Dubreuil, Electrochemical measurement of $\mathrm{SO}_{3}-\mathrm{SO}_{2}$ in process gas streams. Sens. Actuators B 10 (1993) 161-168.

[10] A. Bezerra Martins, A. Lobato, N. Tasić, F.J. Perez-Sanz, P. Vidinha, T.R.L.C. Paixão, L. Moreira Gonçalves, Laser-pyrolyzed electrochemical paper-based analytical sensor for sulphite analysis. Electrochem. Commun. 107 (2019) 106541.

[11] P. Rocha, Â. Vilas-Boas, N. Fontes, D. Geraldo, F. Bento, Evaluation of Polyphenols in Wine by Voltammetric Techniques with Screen Printed Carbon Electrodes. Electroanalysis 32 (2020) 159-165.

[12] R.M. Ramos, P.F. Brandão, L.M. Gonçalves, V. Vyskočil, J.A. Rodrigues, Electrochemical sensing of total sulphites in beer using non-modified screen-printed carbon electrodes. J. Inst. Brew. 123 (2017) 45-48.

[13] R.M. Ramos, L.M. Gonçalves, V. Vyskočil, J.A. Rodrigues, Free sulphite determination in wine using screenprinted carbon electrodes with prior gas-diffusion microextraction. Electrochem. Commun. 63 (2016) 52-55.

[14] L. Xiong, R.G. Compton, Amperometric Gas Detection: A Review. Int. J. Electrochem. Sci. 9 (2014) $7152-$ 7181.

[15] M.C. Buzzeo, C. Hardacre, R.G. Compton, Use of Room Temperature Ionic Liquids in Gas Sensor Design. Anal. Chem. 76 (2004) 4583-4588.

[16] A. Rehman, X. Zeng, Methods and approaches of utilizing ionic liquids as gas sensing materials. RSC Adv. 5 (2015) $58371-58392$.

[17] K.N. Marsh, J.A. Boxall, R. Lichtenthaler, Room temperature ionic liquids and their mixtures- A Review. Fluid Ph. Equilibria 219 (2004) 93-98.

[18] M.C. Buzzeo, R.G. Evans, R.G. Compton, Non-Haloaluminate Room-Temperature Ionic Liquids in Electrochemistry-A Review. Chem. Phys. Chem. 5 (2004) 1106-1120.

[19] M.G. Freire, L.M.N.B.F. Santos, A.M. Fernandes, J.A.P. Coutinho, I.M. Marrucho, An overview of the mutual solubilities of water-imidazolium-based ionic liquid systems. Fluid Ph. Equilibria 261 (2007) 449-454.

[20] M. Malvaldi, C. Chiappe, From molten salts to ionic liquids: effect of ion asymmetry and charge distribution. J. Phys.: Condens. Matter 20 (2008) 035108.

[21] X.-J. Huang, L. Aldous, A.M. O'Mahony, F.J. del Campo, R.G. Compton, Toward Membrane-Free Amperometric Gas Sensors: A Microelectrode Array Approach. Anal. Chem. 82 (2010) 5238-5245.

[22] C. Hu, X. Bai, Y. Wang, W. Jin, X. Zhang, S. Hu, Inkjet Printing of Nanoporous Gold Electrode Arrays on Cellulose Membranes for High-Sensitive Paper-Like Electrochemical Oxygen Sensors Using Ionic Liquid Electrolytes. Anal. Chem. 84 (2012) 3745-3750.

[23] P. Kubersky, J. Altsmid, A. Hamacek, S. Nespurek, O. Zmeskal, An Electrochemical $\mathrm{NO}_{2} \mathrm{Sensor}_{\text {Based on }}$ Ionic Liquid: Influence of the Morphology of the Polymer Electrolyte on Sensor Sensitivity. Sensors 15 (2015) 28421-28434.

[24] A.M. O'Mahony, D.S. Silvester, L. Aldous, C. Hardacre, R.G. Compton, The Electrochemical Reduction of Hydrogen Sulfide on Platinum in Several Room Temperature Ionic Liquids. J. Phys. Chem. C 112 (2008) 77257730 .

[25] G. Hussain, D.S. Silvester, Detection of sub-ppm Concentrations of Ammonia in an Ionic Liquid: Enhanced Current Density Using “Filled” Recessed Microarrays. Anal. Chem. 88 (2016) 12453-12460. 
[26] L.E. Barrosse-Antle, D.S. Silvester, L. Aldous, C. Hardacre, R.G. Compton, Electroreduction of Sulfur Dioxide in Some Room-Temperature Ionic Liquids. J. Phys. Chem. C 112 (2008) 3398-3404.

[27] P. Neta, R.E. Huie, A. Harriman, One-Electron-Transfer Reactions of the Couple $\mathrm{SO}_{2} / \mathrm{SO}_{2}{ }^{-}$in Aqueous Solutions. Pulse Radiolytic and Cyclic Voltammetric Studies. J. Phys. Chem. 91 (1987) 1606-1611.

[28] E. Potteau, E. Levillain, j.-P. Lelieur, Mechanism of the electrochemical reduction of sulfur dioxide in nonaqueous solvents. J. Electroanal. Chem. 476 (1999) 15-25.

[29] C.L. Gardner, D.T. Fouchard, W.R. Fawcett, The Kinetics and Mechanism of the Electroreduction of Sulfur Dioxide in Nonaqueous Media: II . Effects of Electrolyte and Solvent on the Mechanism of Reduction. J. Electrochem. Soc. 128 (1981) 2345-2350.

[30] D.S. Choi, D.H. Kim, U.S. Shin, R.R. Deshmukh, S. Lee, C.E. Song, The dramatic acceleration effect of imidazolium ionic liquids on electron transfer reactions. Chem. Commun. (2007) 3467-3469.

[31] Q. Huang, Y. Hu , J. Wang, K. Jiang, T. Wu, The Principle of Detect $\mathrm{SO}_{2}$ Concentration by Using the Electrochemical Method in Ionic Liquid Wuhan Univ. J. Nat. Sci. 24 (2019) 400-404.

[32] S. Ren, Y. Hou, W. Wu, Q. Liu, Y. Xiao, X. Chen, Properties of Ionic Liquids Absorbing $\mathrm{SO}_{2}$ and the Mechanism of the Absorption. J. Phys. Chem. B 114 (2010) 2175-2179.

[33] J. Lee, G. Du Plessis, D.W.M. Arrigan, D.S. Silvester, Towards imroving the robustness of electrochemical gas sensors: impact of PMMA addition on the sensing of oxygen in an ionic liquid. Anal. Methods 7 (2015) 73277335.

[34] R.P. Martin, D.T. Sawyer, Electrochemical Reduction of Sulfur Dioxide in Dimethylformamide. Inorg. Chem. 11 (1972) 2644-2647.

[35] E. Jacobsen, D.T. Sawyer, Electrochemical reduction of sulfur dioxide at a mercury electrode. J. Electroanal. Chem. 15 (1967) 181-192.

[36] J. Wandt, J. Lee, D. Arrigan, D.S. Silvester, A lithium iron phosphate reference electrode for ionic liquid electrolytes. Electrochem. Commun. 93 (2018) 148-151.

[37] J. Lee, C. Caporale, A. McKinley, R. Fuller, D. Silvester-Dean, Electrochemical Properties of a Verdazyl Radical in Room Temperature Ionic Liquids. Aust. J. Chem. (accepted for publication) (2020)

[38] J.A. O'Brien, J.T. Hinkley, S.W. Donne, Electrochemical Oxidation of Aqueous Sulfur Dioxide II. Comparative Studies on Platinum and Gold Electrodes. The Electrochemical Society 159 (2012) 585-593.

[39] C.A. Betty, S. Choudhury, Charge carrier transport in nanocrystalline $\mathrm{SnO}_{2}$ thin film sensor and temperature dependence of toxic gas sensitivity. Sens. Actuators B 237 (2016) 787-794.

[40] Q. Zhou, W. Zeng, W. Chen, L. Xu, R. Kumar, A. Umar, High sensitive and low-concentration sulfur dioxide $\left(\mathrm{SO}_{2}\right)$ gas sensor application of heterostructure NiO-ZnO nanodisks. Sens. Actuators B 298 (2019) 126870.

[41] L. Liu, S. Liu, Oxygen Vacancies as an Efficient Strategy for Promotion of Low Concentration $\mathrm{SO}_{2} \mathrm{Gas}$ Sensing: The Case of Au-Modified $\mathrm{SnO}_{2}$. ACS Sustain. Chem. Eng. 6 (2018) 13427-13434.

[42] M. Tariq, J.A.P. Carvalho, I.M. Marrucho, J.N.C. Lopes, L.P.N. Rebelo, Viscosity of (C2-C14) 1-alkyl-3methylimidazolium bis(trifluoromethylsulfonyl)amide ionic liquids in an extended temperature range. Fluid Phase Equilib. 301 (2011) 22-32.

[43] A. Bhattacharjee, A. Luis, J.H. Santos, J.A. Lopes-da-Silva, F.M. G.;, P.J. Carvalho, J.A.P. Coutinho, Thermophysical properties of sulfonium- and ammonium-based ionic liquids. Fluid Phase Equilib. 381 (2014) $36-45$

[44] H.F.D. Almeida, J.N.C. Lopes, L.P.N. Rebelo, J.A.P. Coutinho, M.G. Freire, I.M. Marrucho, Densities and Viscosities of Mixtures of Two Ionic Liquids Containing a Common Cation. J. Chem. Eng. Data 61 (2016) 2828-2843.

[45] F.M. Gacino, T. Regueira, L. Lugo, M.J.P. Comunas, J. Fernandez, Influence of Molecular Structure on Densities and Viscosities of Several Ionic Liquids. J. Chem. Eng. Data 56 (2011) 4984-4999.

[46] K.R. Harris, M. Kanakubo, L.A. Woolf, Temperature and Pressure Dependence of the Viscosity of the Ionic Liquid 1-Butyl-3-methylimidazolium Tetrafluoroborate: Viscosity and Density Relationships in Ionic Liquids. J. Chem. Eng. Data 52 (2007) 2425-2430.

[47] C.M.S.S. Neves, P.J. Carvalho, M.G. Freire, J.A.P. Coutinho, Thermophysical properties of pure and watersaturated tetradecyltrihexylphosphonium-based ionic liquids. J. Chem. Thermodyn. 43 (2011) 948-957.

[48] J.D. Holbrey, K.R. Seddon, R. Wareing, A simple colorimetric method for the quality control of 1-alkyl-3methylimidazolium ionic liquid precursors. Green Chem. 3 (2001) 33-36.

[49] A.M. O'Mahony, D.S. Silvester, L. Aldous, C. Hardacre, R.G. Compton, Effect of Water on the Electrochemical Window and Potential Limits of Room-Temperature Ionic Liquids. J. Chem. Eng. Data 53 (2008) 2884-2891.

[50] T. Köddermann, C. Wertz, A. Heintz, R. Ludwig, The Association of Water in Ionic Liquids: A Reliable Measure of Polarity. Angew. Chem., Int. Ed. 45 (2006) 3697-3702.

[51] J.E.S.J. Reid, A.J. Walker, S. Shimizu, Residual water in ionic liquids: clustered or dissociated? Phys. Chem. Chem. Phys. 17 (2015) 14710-14718. 
[52] J. Lee, G. Hussain, N. López-Salas, D.R. MacFarlane, D.S. Silvester, Thin films of poly(vinylidene fluorideco-hexafluoropropylene)-ionic liquid mixtures as amperometric gas sensing materials for oxygen and ammonia. Analyst 145 (2020) 1915-1924. 